\title{
COVID-19 - 2021: A New, Less Predictable Phase of the Pandemic
}

\author{
Jeremy Farrar
}

It is just over a year ago that what we now know as coronavirus disease 2019 (COVID-19) first emerged in Wuhan, China (1). In twelve short months every village, every city in every continent has been affected. Hundreds of millions of people have been infected and recovered and over two million of people have tragically died from COVID-19. In reality, many more have lost loved ones. Yet we may still be closer to the start of this pandemic than to the end.

We knew a year ago that this virus had all the characteristics capable of causing a devastating global pandemic. An animal virus that had crossed the species barrier and could infect humans, for which humanity had no immunity. We knew there was human-tohuman transmission, we knew people were infectious when they were asymptomatic or pre-symptomatic, that it could cause a mild illness and also a very severe illness leading tragically to people dying (2). We knew the genomic sequences of the virus and we knew we had no diagnostic tests, no specific treatments, or vaccines. We also knew this initially emerged in a very densely populated city with highly connected transport links. Since we had all that information at the end of January 2020, the trajectory of the pandemic has in many ways been highly predictable.

At the dawn of the Lunar New Year, we now face a much less predictable year.

The recent emergence of more transmissible COVID-19 variants with higher case fatality poses a serious threat to efforts to control the pandemic (3-4). Those variants already identified render anti-viral treatments ineffective, evade immunity from natural infection and, with emerging evidence that some variants reduce efficacy of the first-generation vaccines. It is inevitable that further variants will emerge that pose a more significant threat to vaccine efficacy. Most first-generation vaccines and treatments target a single virus protein, the spike protein, and are very vulnerable to mutations and emergence of new strains. Given that we are currently only finding variants where we have the capability to sequence, and not necessarily where they are occurring, this could already be the case. It is not coincidence that the three new variants have been picked up in the last quarter of 2020, we can expect a more rapid evolution of the virus in 2021 and more new variants as it adapts to humans (biological adaptation) and is now under increasing immunological pressure from infection and vaccination (immunological adaptation).

Since viral mutation is fundamentally a function of global prevalence, there is an imperative to reduce transmission everywhere. Otherwise, mutations will erode the efficacy of our tools faster than we can adapt them. In this instance the adage "no one is safe until everyone is safe" is not just rhetoric, but epidemiological fact. A massive global reduction in prevalence would result in slower evolution and thus make the virus easier to control. We have either to face a vicious cycle of greater prevalence leading to faster mutation and continued reverberation of this pandemic, a pandemic within a pandemic. Or a virtuous cycle of lower prevalence resulting in less mutation and the ability to stay ahead of this pandemic.

Science and international collaboration have always been the exit strategy from this pandemic. That is even more true today. We need to combine the best tools where-ever they may be developed. This could mean combining the best vaccines developed in China with the best vaccines developed in the rest of the world. A global effort to assess these vaccines together and demonstrate which are the best combinations is now urgent. Assessing all possible vaccination strategies is now imperative, for instance priming with an inactivated or other whole virus vaccine followed by a boost with specific targeted vaccine is certainly worth pursuing as part of a matrix of combinations that can elicit the strongest, longest lasting immune response that protects against existing variants and prevents new variants from emerging. This needs international cooperation on an unprecedented scale to bring together the best vaccines for humanity and end this devastating pandemic. The same approach needs to be applied to the development of new treatments, 
diagnostics, global genomic surveillance and to the provision of oxygen, personal protective equipment to protect health care workers, and support for health systems to deliver these essential tools.

The first pandemic of the 21 st Century has not only had an impact through the direct health consequences of COVID-19. It has impacted every sector of all our societies. This can be framed as four concentric circles: ripples from a stone thrown into a pond. The innermost circle is the immediate impacts of the virus itself, the direct consequences of infection, the illnesses, hospitalizations, and the tragic death toll. That has already been a devastating blow and is still reverberating around the world. However, it may prove to be the smallest of the four circles.

The next, the second larger circle is the indirect health effects; the secondary consequences on all other healthcare. We've already seen in many parts of the world the indirect COVID-19 impact on all other healthcare - heart attacks, tuberculosis (TB) screening and treatment, maternal/child health and for routine vaccinations. The impact on all our well-being and mental health may be even more profound. Other people miss cancer screenings, and cancers will be missed; others, simply fail to get enough exercise, and live shorter lives as a result.

The third circle, rippling out from the second, will be larger still; the social and economic impacts. The economic consequences are perhaps obvious - the joblessness, the shrinking economies; the lack of international trade, increasing debt, fall in remittances, which the International Monetary Fund (IMF) estimates will cost the world 12 trillion USD. More than that, pandemics, like all crises, open up existing fractures in society: they hit the poor harder than the rich; it leads to mistrust between the governed and the governing. The educational impacts of closed schools will hit disadvantaged children and their families the hardest. There is often a fear of outsiders, people "not like us," there often needs to be someone to blame. The political consequences could be severe. If a government is seen as having failed to protect its citizens at a time of crisis there is a loss of trust: the government was not there for its people when it was needed the most. Most of all it amplifies inequalities. And that leads to a fourth circle: the geopolitics. As national governments suffer criticism from their citizens for (perceived or real) failure to protect them, the instinct will always be to blame others, to deflect. This played out in 2020 and is happening again in 2021 as some sought to blame others for the pandemic, the rise in vaccine nationalism, the inequitable access to the critical tools needed to end this pandemic for everyone, everywhere.

None of this is inevitable. For each of the four circles, there are policy responses, nationally and globally. We must improve the public health, clinical, and disease-surveillance measures that can reduce the impact as it continues to reverberate around the world and prepare for future waves. We can also ensure that we invest now in health systems available for all needs, including the resilience to prevent and cope with such inevitable future pandemic shocks.

We can, also, mitigate the third circle, the social and political impacts. We must act on the inequalities in all our societies, rebuild trust in a critical role for government and debt relief for poorer countries would go some way to lessening the economic devastation in the developing world. We need to prepare for the long term changes the pandemic will evoke, invest in education and the training for jobs of the future not the past, opportunities for young people, transition to new, greener economies, fight corruption and value resilience as well as efficiency.

And when it comes to the fourth circle, similarly we face a choice. We can choose to go down a nationalistic, populist routes, blaming others for our problems, amplifying what divides, rather than building on what binds us together and choose to work together to forge a better more equitable peaceful future. There are historical parallels which we can draw on from the 20th century when our parents and grandparent's generation emerged from devastating crisis to forge a much stronger togetherness with the setting up of the United Nations, the World Health Organization, and many others, which bind our small world together

COVID-19 has been and continues to be devastating, but pandemics are not the only global challenges of the 21 st Century. In the next few years, we will also need to collectively address the truly global challenges of climate change, access to clean water and green sustainable energy, inequality, antimicrobial resistance, and inevitably more complex and frequent epidemics. Just as with COVID-19, those problems will not be defeated by insular nationalism, blaming others, or by drifting into a more polarized world which makes us all more vulnerable, but by creating and enhancing means of international cooperation. It is not inevitable that the first circle ripples out to the fourth in the most ruinous way possible but avoiding it will take people laying out these problems honestly, 
and then being equally honest about our ways out of them. We will face such a choice. A choice that will go a long way to defining how we address all these great global challenges of the 21 st Century.

doi: $10.46234 / \mathrm{ccdcw} 2021.032$

\# Corresponding author: Jeremy Farrar, J.Farrar@wellcome.org.

Submitted: February 07, 2021; Accepted: February 08, 2021

\section{REFERENCES}

1. Tan WJ, Zhao X, Ma XJ, Wang WL, Niu PH, Xu WB, et al. A novel

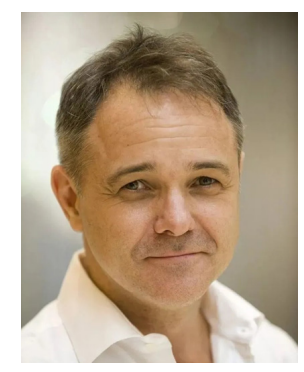

Sir Jeremy Farrar, PhD

Director, Wellcome Trust coronavirus genome identified in a cluster of pneumonia cases Wuhan, China 2019-2020. China CDC Wkly 2020;2(4):61-2. http://dx.doi.org/10.46234/ccdcw2020.017.

2. The Novel Coronavirus Pneumonia Emergency Response Epidemiology Team. The epidemiological characteristics of an outbreak of 2019 novel coronavirus diseases (COVID-19) - China, 2020. China CDC Wkly 2020;2(8):113 - 22. http://dx.doi.org/10.46234/ccdcw2020.032.

3. Chen HY, Huang XY, Zhao X, Song Y, Hao P, Jiang H, et al. The first case of new variant COVID-19 originating in the United Kingdom detected in a returning student - Shanghai Municipality, China, December 14, 2020. China CDC Wkly 2021;3(1):1 - 3. http://dx.doi.org/ $10.46234 / \mathrm{ccdcw} 2020.270$.

4. Chen FJ, Li BS, Hao P, Song Y, Xu WB, Liu NK, et al. A case of new variant COVID-19 first emerging in South Africa detected in airplane pilot - Guangdong Province, China, January 6, 2021. China CDC Wkly 2021;3(2):28 - 29. http://dx.doi.org/10.46234/ccdcw2021.007. 